\title{
Influential Factors of Residential Commodity Price Changes in Sanya
}

\author{
Ying-Yu Du ${ }^{1}$, Yong-Qi Huang ${ }^{2}$, Can-Xu Yao ${ }^{3} \&$ Yuan-Biao Zhang ${ }^{4,5}$ \\ ${ }^{1}$ Financial Management of International Business School, Jinan University, Zhuhai, Guangdong Province, China \\ ${ }^{2}$ Finance Department of International Business School, Jinan University, Zhuhai, Guangdong Province China \\ ${ }^{3}$ Electrical and Information College of Jinan University, Zhuhai, Guangdong Province China \\ ${ }^{4}$ Innovation Practice Base of Mathematical Modeling of Jinan University, Zhuhai, Guangdong Province China \\ ${ }^{5}$ Key Laboratory of Product Packaging and Logistics of Guangdong Higher Education Institutes, Jinan \\ University, Zhuhai, Guangdong Province, China \\ Correspondence: Yong-Qi Huang, Finance Department of International Business School, Jinan University, \\ Qianshan Road 206\#, Zhuhai City, Guangdong Province, Post No. 519070, China. Tel: 86-136-8032-4464. \\ E-mail: 3095511901@qq.com
}

Received: November 4, 2018

Accepted: November 16, 2018

Online Published: November 20, 2018

doi:10.5539/ijef.v10n12p96

URL: https://doi.org/10.5539/ijef.v10n12p96

\begin{abstract}
Residential commodity price is not only an important index of government macro-control, but also an important livelihood topic in society. The purpose of this paper is to take Sanya as an example to make an empirical analysis on the relationship between the factors affecting commodity housing prices, and their effects on housing prices. By using pearson correlation analysis, factor analysis and principal component regression method, it is found that the main factors influencing the housing price in Sanya are the housing sales area, the gross domestic product, the per capita disposable income, and the land price level of residential land. Among them, housing sales area and Sanya city house price changes in the opposite direction, the regional gross domestic product, per capita disposable income, residential land price level plays a positive role in housing prices.
\end{abstract}

Keywords: residential commodity price, factor analysis, principle component regression

\section{Introduction}

\subsection{Background Description}

In 2010, the state introduced policies to promote the integration of tourism and other industries in the province and promote economic transformation, which led to another surge in commodity housing prices in Hainan province. Commodity residential prices of Sanya overnight per square meter rose by 3000 yuan to 8000 yuan. Therefore, the purpose of this paper is to qualitatively and quantitatively analyze the influencing factors of commercial housing prices in Sanya under the influence of Hainan Free Trade Zone. There are many factors affecting the price of commercial housing, including economic factors, demographic factors, environmental factors, policy factors, and psychological factors. This paper mainly studies the impact of economic factors on housing prices in Sanya, because the economic development level of a region has regular fluctuations on housing prices, and some factors have an impact on housing prices at a certain point, such as the number of infrastructure and policy factors.

In addition to studying the impact of economic factors on housing prices in Sanya, the impact of supply and demand on housing prices is also studied in this paper. In the market economy, when the market supply and demand are in equilibrium, commodity prices are also in a stable state. Once the market supply and demand balance is broken, the price of goods will change. Commercial housing prices will be affected by market supply and demand. Considering that tourism income accounts for a large proportion of Sanya's economic income, tourism income is also an influential factor in the study of Sanya's commodity housing prices.

\subsection{Relevant Scholarship}

The influence factor of commodity housing price is a very hot topic in China. With the economic development of Hainan Province, the commodity housing prices in Sanya City also have a considerable impact. The purpose of this paper is to study the factors affecting the price of commercial housing in Sanya City. There are many 
scholars to study the price of commercial housing, the results are as follows:

Jafar and Ali Hosseini (2018) made a research aimed to investigate the role of socio-economic variables on the prices of land and housing in the city of Mashhad. The results of the impact of socio-economic variables on land and housing prices, using path analysis, showed that the variables of income, occupational status, and educational level had the highest effect on the price of land and housing. Ming-Ming (2018) pointed out that the rise in land prices will directly lead to a rise in housing prices in the region, which will lead to a series of indicators such as GDP, per capita consumer spending and consumer price indices. Bin and Jun-Ping (2017) believe that commodity housing prices in Guangzhou have experienced a sharp rise, and that the fundamental driving factor is still a sharp increase in housing consumption demand from urban residents brought about by economic development and population growth. Research Zainora, Norzailawati, and Tuminah (2016) for the purchase of circumstances sensibility Malaysia survey showed that public open space and housing prices showed a weak positive correlation. What's more, Qiu-Xia and Wen-Kai (2013) based on the theory of grey relational degree analysis, analyzed the main factors influencing the commodity housing price, and obtained six relatively high correlation factors: the consumer price index of residents and the investment of commercial housing development. Loan interest rate, per capita GDP, commodity residential sales area, urban residents' per capita disposable income. Yuan (2012) proposed that main factors influencing residents' purchase willing are traffic condition, location, price, environment, education environment, property management and so on. Anglin (2006) used the vector autoregressive model in the Toronto real estate trend research to find that the consumer price index, employment rate and loan interest rate are the main factors affecting the trend of housing prices.

\subsection{Research Design}

This paper mainly uses pearson correlation analysis, factor analysis and principal component regression to analyze influence factors of residential commodity price in Sanya city. Firstly, this paper sums up the influential factors that influence the price of commercial housing, and combines the characteristics of Sanya City, carries on the qualitative analysis to the influence factor found. Secondly, based on the Pearson correlation analysis, the factors influencing the house price which does not pass the double tail test is eliminated. By using factor analysis, the relationship between the influencing factors of house price is obtained. Finally, using principal component regression method, taking the commodity housing price in Sanya as dependent variable and the public factor in Sanya as independent variable, the regression equation model of Sanya housing price is obtained, then carry on quantitative analysis to the influence factor of house price.

\section{Theoretical Models}

\subsection{Pearson Correlation Analysis}

Pearson correlation, also known as product difference correlation (or product moment correlation), is a method to calculate linear correlation proposed by British statistician Pearson in the 20th century. Pearson correlation coefficient is used to measure whether two data sets are above a line, and it is used to measure the linear relationship between fixed distance variables. The greater the absolute value of the correlation coefficient, the stronger the correlation: the closer the correlation coefficient is to 1 or -1 , the stronger the correlation degree is, and the closer the correlation coefficient is to zero, the weaker the correlation degree is.

The calculation formula is as follows:

$$
\gamma_{x, y}=\frac{N \sum x_{i} y_{i}-\sum x_{i} \sum y_{i}}{\sqrt{N \sum x_{i}^{2}-\left(\sum x_{i}\right)^{2}} \sqrt{N \sum y_{i}^{2}-\left(\sum y_{i}\right)^{2}}}
$$

The range of application of Pearson correlation coefficient is as follows:

1). There is a linear relationship between the two variables, both of which are continuous data.

2). The population of the two variables is normal distribution, or close to normal single peak distribution.

3). The observations of the two variables are paired, and each pair of observations is independent of each other.

Data used in this paper are all meet the above conditions.

\subsection{Factors Analysis}

The basic purpose of factor analysis is to use a few factors to describe the relationship between many indicators or factors. Most of the information of the original data is reflected by a few factors. The steps of factor analysis are as follows:

Step 1. Data standardization

In this paper, we use zero-mean normalization. The processed data conform to the standard normal distribution, 
that is, the mean value is 0 , and the standard deviation is 1 . The formula is as follows:

$$
z_{i j}=\frac{x_{i j}-\mu_{j}}{\sqrt{s_{j}}},(i=1,2, \ldots, \mathrm{n})
$$

$x_{i j}$ means the $j^{\text {th }}$ indicator of the influential factors and the $i^{\text {th }}$ housing price, and each indicator will be standardized and converted to $Z_{i j} . \mu_{j}$ means average value, $\sqrt{s_{j}}$ means standard deviation.

\section{Step 2. Data testing}

Before factor analysis, Bartlett sphericity test and KMO test are needed. Data analysis software SPSS can be used to do above data tests. The larger the KMO value, the more common factors among variables are more suitable for factor analysis. If the value of KMO is more than 0.5, and the value of the Bartlett sphericity test sig (the $\mathrm{P}$ value) is less than 0.05 , the data can be used for factors analysis.

\section{Step 3. Factor selection}

(1) Calculating the correlation matrix of standardized data

Correlation coefficient matrix $R$ is as follows:

$$
R=\left[\begin{array}{cccc}
\gamma_{11} & \gamma_{12} & \ldots \ldots & \gamma_{1 j} \\
\gamma_{21} & \gamma_{22} & \ldots \ldots & \gamma_{2 j} \\
\ldots \ldots & \ldots \ldots & \ldots \ldots & \ldots . . \\
\gamma_{i 1} & \gamma_{i 2} & \ldots \ldots & \gamma_{i j}
\end{array}\right]
$$

$\gamma_{i j}$ is the correlation coefficient between the $j^{\text {th }}$ indicator and the $i^{\text {th }}$ indicator.

(2) Calculating the eigenvalues and Eigenvectors of the correlation matrix

Calculate the eigenvalues of the Correlation coefficient matrix: $\left(\lambda_{1}, \lambda_{2}, \lambda_{3}, \ldots, \lambda_{n}>0\right)$, and corresponding feature vectors are $\left(p_{1}, p_{2}, p_{3}, \ldots, p_{n}\right)$. Mathematically, the eigenvector of the linear transformation is a nondegenerate vector whose direction is invariant under the transformation. The scale of the vector scaled under this transformation is called its eigenvalue.

(3) Calculating variance contribution rate and cumulative variance contribution rate

The characteristic root of the correlation matrix is equal to the variance of the corresponding principal component, which reflects the proportion of all the original data contained by the $i^{t h}$ principal component and the contribution of each principal component.

The variance contribution rate of the $i^{t h}$ principal component is defined as:

$$
\alpha_{k}=\frac{\lambda_{k}}{\sum_{i=1}^{p} \lambda_{i}}
$$

The cumulative variance contribution rate is:

$$
\beta_{k}=\frac{\sum_{i-1}^{k} \lambda_{i}}{\sum_{i=1}^{p} \lambda_{i}}
$$

The greater the cumulative variance contribution, the more the $i^{\text {th }}$ principal component contain the original information.

\section{Step 4. Factor determination}

There are $\mathrm{p}$ factors, they are $\left(F_{1}, F_{2}, F_{3}, \ldots, F_{n}\right)$, in which the first $\mathrm{m}$ factors contain the total amount of data information (that is, its cumulative contribution rate) is not lower than 80 , the former $\mathrm{m}$ factors should be used to reflect the original evaluation index.

\section{Step 5. Factor rotation}

In order to simplify the structure of factor load matrix by factor analysis method and to explain the main factor in a professional way, the factor load matrix is often transformed or called factor rotation. The most commonly used method is the orthogonal rotation method with the largest variance. Each column of elements in the rotated 
factor load array is separated as far as possible, that is, polarized to 0 or 1 , so that each main factor corresponds to only a few variables with high loads. The other loads are very small, and each variable has high load on a few main factors, and the other loads are very small. In this paper, we use the maximum orthogonal rotation method to achieve the factor rotation.

\subsection{Principle Component Regression}

Principle Component Regression is a method to analyze multivariate collinearity problem. After eliminating multiple collinearity in regression model by principal component analysis, the principal component variable is used as independent variable for regression analysis, and then the original variable is replaced back to the new model according to score coefficient matrix.

Step 1. Determine the number of principal components

The number of principal components is determined by accumulative contribution rate and factor load matrix. Principal components can be confirmed under the condition that the cumulative contribution rate is more than 80\%. In this paper, there is just one principal component $Z_{1}$.

Step 2. Establishment of a linear regression model between principal component and housing price

The housing price in Sanya city is regarded as dependent variable and principal component $Z_{1}$ as independent variable. The linear regression model is established and the regression equation is obtained. The formula is as follows:

$$
y=a+b Z_{1}
$$

Step 3. Establishment of a linear regression model between influential factors and housing price

The principal component $Z_{1}$ is regarded as dependent variable and factors influencing Sanya house price as independent variable, a multivariate linear regression model is established. The formula is as follows:

$$
Z_{1}=\sigma_{1} X_{1}+\sigma_{2} X_{2}+\ldots+\sigma_{n} X_{n}
$$

Step 4. Replace the formula of the third step into the formula of the second step

The regression equation obtained in the third step is substituted into the first step. Then principal component Z1 is eliminated. Finally, the principal component regression model affecting the house price in Sanya city is obtained. The formula is as follows:

$$
y=a+\sigma_{1}^{\prime} X_{1}+\sigma_{2}^{\prime} X_{2}+\ldots+\sigma_{n}^{\prime} X_{n}
$$

\section{Empirical Analysis}

\subsection{Data Resources}

Data used in this paper are collected and tested for accuracy and completeness. Through the Haikou Statistical Yearbook, Hainan Statistical Yearbook and China Land Price Information Service platform, this paper collected and analyzed the housing prices, the residential investment in GDP, real estate development in the region, the housing sales area, the total tourism income, per capita disposable income and residential land price level. in Sanya City in Each month of 2017. Six alternative indicators affecting Commodity Housing prices are as Table 1:

Table 1. Six alternative indicators affecting commodity housing prices

\begin{tabular}{ccc}
\hline Index & Index meaning & Unit \\
\hline $\boldsymbol{X}_{\mathbf{1}}$ & Housing investment in real estate development & 100 million yuan \\
$\boldsymbol{X}_{2}$ & Housing sales area & Ten thousand per square metre \\
$\boldsymbol{X}_{\mathbf{3}}$ & Total tourism revenue & 100 million yuan \\
$\boldsymbol{X}_{\mathbf{4}}$ & Regional GDP & 100 million yuan \\
$\boldsymbol{X}_{\mathbf{5}}$ & Per capita disposable income & yuan \\
$\boldsymbol{X}_{\mathbf{6}}$ & Residential land price level & Ten thousand per square metre \\
\hline
\end{tabular}

\subsection{Pearson Correlation Analysis Result}

Pearson correlation analysis is used to measure whether two data sets are on one line, and it is used to measure the linear relationship between fixed distance variables. Therefore, it is reasonable to use Pearson correlation analysis to measure the impact of various factors on housing prices. 
Based on the selected six alternative housing price impact indicators, the Pearson correlation coefficient between each index and the commodity housing price in Sanya is calculated by means of the analysis of SPSS software. The result is shown in the following Table 2:

Table 2. Pearson correlation coefficient between House prices and various factors

\begin{tabular}{cc}
\hline Influential factors & Housing Price in Sanya \\
\hline Housing investment in real estate development & 0.361 \\
Housing sales area & $-0.605^{*}$ \\
Total tourism revenue & 0.152 \\
Regional GDP & $0.966^{* *}$ \\
Per capita disposable income & $0.941^{* *}$ \\
Residential land price level & $0.980^{* *}$ \\
\hline
\end{tabular}

According to the analysis results of Sanya City, the two indexes of real estate investment and total tourism income can be excluded, because the Pearson correlation coefficient between these two indexes and house prices is small, and the factors that have not passed the double-tail test.

The remaining factors are: housing sales area, regional gross domestic product, per capita disposable income, residential land price level. There is a negative correlation between the housing sales area and the housing price. When the supply of the commercial housing is larger than the sales area, the increase of the sales area will make the house price decline. The remaining three factors are positively correlated with housing prices. Among them, the area of housing sales, regional gross domestic product, per capita disposable income, residential land prices and the level of the correlation coefficient is: $-0.605,0.966,0.941,0.980$.

\subsection{Factors Analysis Result}

Before factor analysis, Bartlett sphericity test is needed. Through KMO sample measure to test whether the data is suitable for factor analysis, the larger the value of $\mathrm{KMO}$, the more common factors among variables are more suitable for factor analysis. According to Kaiser's view, factor analysis is not appropriate if the value of KMO is less than 0.5. Result of the Bartlett sphericity test and KMO test are as Table 3.

Table 3. Result of the Bartlett sphericity test and KMO test

\begin{tabular}{ccc}
\hline KMO & 0.799 \\
\hline Bartlett sphericity test & Approximate Chi-square & 52.594 \\
& Degree of freedom & 6 \\
& Significance & 0 \\
\hline
\end{tabular}

According to the results in Table 3, the value of KMO is 0.799 , it shows that all the data of Sanya city are suitable for factor analysis. If the null hypothesis is rejected, this means that the variable is independent of each other. The significant result of 0.000 indicates the negation of the invalid hypothesis.

After the above Bartlett sphericity test, we know that the influencing factors in Sanya city are suitable for factor analysis. The factor analysis is carried out with the statistical software SPSS, and the characteristic value, principal component contribution rate and cumulative contribution rate of each factor analysis in Sanya city are obtained, as shown in the Table 4.

Table 4. Result of characteristic value, contribution rate and cumulative contribution rate

\begin{tabular}{cccc}
\hline principal component & characteristic value & Contribution rate (\%) & Cumulative contribution rate (\%) \\
\hline $\mathrm{Z}_{1}$ & 3.423 & 85.585 & 85.585 \\
$\mathrm{Z}_{2}$ & 0.481 & 12.033 & 97.618 \\
$\mathrm{Z}_{3}$ & 0.074 & 1.850 & 99.468 \\
$\mathrm{Z}_{4}$ & 0.021 & 0.532 & 100.00 \\
\hline
\end{tabular}

The results showed that the characteristic values of the principal components in Sanya city are 3.423, 0.481, 0.074 and 0.021 respectively. The contribution rate of the first principal component was $85.585 \%$. Therefore, there is one principal component that explains the housing price in Sanya city. 


\subsection{Principle Component Regression}

Factor analysis is an effective "dimensionality reduction" method. It provides a method to simplify complex things, but factor analysis can not directly reflect the correlation between "common factors" and analytical objectives. That is to say, all kinds of influence factors and the city commodity housing price correlation degree is not clear.

Based on the factor analysis of the influencing factors of the house price in Sanya, the four indexes that have the greatest influence on the house price in Sanya are the area of house sales, the regional gross domestic product, the per capita disposable income, and the land price level of residential land. Get a common factor and set it be $Z_{1}$. The matrix of variable and factor score coefficients in Sanya city is shown in the following Table 5.

Table 5. The matrix of variable and factor score coefficients in Sanya city

\begin{tabular}{cc}
\hline & The first principal component $\left(\mathrm{Z}_{1}\right)$ \\
\hline Housing sales area $\left(\mathrm{X}_{2}\right)$ & -0.227 \\
Regional $\operatorname{GDP}\left(\mathrm{X}_{4}\right)$ & 0.285 \\
Per capita disposable income $\left(\mathrm{X}_{5}\right)$ & 0.279 \\
Residential land price level $\left(\mathrm{X}_{6}\right)$ & 0.285 \\
\hline
\end{tabular}

According to the Table 5, we can get the following formula of the influence factors and the first principal component. The formula is as follows:

$$
Z_{1}=-0.227 X_{2}+0.285 X_{4}+0.279 X_{5}+0.285 X_{6}
$$

Then, by using MATLA's regress function, the regression equation between the commodity housing price and the principal components in Sanya City can be obtained. The formula is as follows:

$$
y=-15077+17.5804 Z_{1}
$$

After obtaining the regression equation of house price in Sanya city, the accuracy of the regression model can be verified by the significance and fitting test of the regression equation. The main purpose of significance test is to test whether the price of commercial housing in Sanya has a close relationship with the principal components. After the significance test of the regression equation of Sanya City, the significance level of the model $\mathrm{p}=2.04 \times 10^{-6}$, which is much less than 0.01 . And its F-statistic is 94.6615 , which is much more than F-measurement. It is proved that the regression equation passes the significance test. When the model test is significant, a fit test is required. The judging coefficient of Sanya city obtained from the inspection is: $R^{2}=0.9045$, which shows that the regression equation has passed the fitting test.

Finally, we can get the regression equation of the house price and the factors affecting Sanya city. The formula is as follows:

$$
y_{2}=-15077-3.9908 X_{2}+5.0104 X_{4}+4.9049 X_{5}+5.0104 X_{6}
$$

Through the regression equation of the commodity housing price in Sanya, quantitative analysis is made on the influencing factors of the housing price. It can be seen from the formula that the regional gross domestic product and the land price level of residential land have great influence on the commodity housing price in Sanya city.

\section{Conclusion}

Based on the empirical research of this paper, the factors affecting housing prices in Sanya City are mainly real estate development residential investment, housing sales area, total tourism revenue, regional GDP, per capita disposable income, and residential land price level. This paper mainly uses the regression model to analyze the impact of different indicators on housing prices. The specific results are as follows:

1) Real estate development residential investment is an important indicator to reflect the supply of real estate market. The greater the investment in real estate development, the more adequate the supply of commercial housing, leading to the rise of commodity housing prices.

2) Housing sales area this indicator reflects the real estate market demand. The change of demand will affect the fluctuation of commodity housing price. When supply exceeds demand, it leads to a drop-in house price.

3) Total tourism revenue this indicator reflects the development of tourism in Sanya. Economic development in Sanya is largely driven by tourism. Therefore, the total tourism income can reflect the economic development of Sanya, and the higher the total tourism income, the higher the commodity housing prices will rise. 
4) Regional GDP refers to the final result of the production activities of all resident units in the region in a certain period of time, and it is an important indicator to reflect the economic development of a region. Regional GDP and Sanya city commodity housing prices show the same direction of change.

5) The per capita disposable income is the most important factor affecting the housing price, which reflects the influence of economy on the housing price. It is a measure of the income level of residents in a region, it can reflect the ability of individuals to buy a house, generally speaking, the more disposable income per capita, the stronger the ability to buy a house.

6) Land prices and the supply of commercial housing is closely related. The land price of residential land increases and the building cost increases, which directly affects the rise of house price.

The most important contribution of this paper is to study the impact of different influencing factors on the housing prices of commercial housing in Sanya from the perspective of economic factors and supply and demand. In addition, it also includes the indicator of total tourism revenue to study whether the price of commercial housing in Sanya will be affected by tourism. On this basis, a multivariate linear regression model is established and some significance tests are carried out to illustrate the general ideas and processes of using econometrics to study economic activities through regression analysis. This has certain guiding significance for the healthy development of the residential market in Sanya, and has found the main reason for the current high housing prices.

However, this paper still has some limitations and areas for improvement. In this paper, the factors affecting the price of commercial housing are actually seeking the operation law of the real estate economy and the residential market. Since residential real estate itself is a very complicated system, to fully reflect and explain this system, a complete set of indicator system is needed. Therefore, the six factors selected in the paper and the analysis based on these six factors can only be Reflecting some rules of residential real estate from one side. The future may be more in-depth study by collecting more influence in Sanya City, prices of index data, increasing the time span of the sample, factors affecting the price of commercial housing in Sanya City.

\section{References}

Anglin, P. (2006). Local dynamics and contagion in real estate markets. The International Conference on Real Estates and Macro Economy, Beijing, July, 2006. Retrieved from https://www.researchgate.net/publication/255634159_Local_dynamics_and_contagion_in_real_estate_mark ets

Bin, X., \& Jun-Ping, L. (2017). The Growth Trend of Guangzhou Residential Price with Market Rule and Government Policy. China Real Estate, (24), 3-12. https://doi.org/10.13562/j.china.real.estate.2017.24.002

Hai-Yang, L. (2010). On elements of commercial house prices_- Taking Yinchuan as an example. Ningxia Social Sciences, (04), 57-60. $\quad$ Retrieved from http://www.wanfangdata.com.cn/details/detail.do?_type=perio\&id=nxshkx201004011

Hui, S. (2010). The hierarchical structure of Macro-control under the Vision of "National Coordination" - Taking the Macro-control of Commodity Housing Price as the Analysis sample. Economic Law Research, 9, 203-217. Retrieved from http://kns.cnki.net/kcms/detail/detail.aspx $?$ dbcode=CJFD\&filename=JFYJ201000013\&dbname=CJFDLAS N2014

Jing-Yi, W. (2016). An empirical Analysis on the influencing factors of Commodity Housing Price. Northern Economy and Trade, (01), 47-48. https://doi.org/10.3969/j.issn.1005-913X.2016.01.023

Mirkatouli, J., Hosseini, A., \& Samadi, R. (2018). Evaluating and analysis of socio-economic variables on land and housing prices in Mashhad, Iran. Sustainable Cities \& Society. Retrieved from https://www.sciencedirect.com/science/article/pii/S2210670717311964?via\%3Dihub

Xi, L, \& Quan, Y. (2013). Study on Effects of Price Regulation Policies for Commercial Housing in China. Innovation, 7(03), 87-90+125+128.

Yan, X., \& Min, L. (2017). Present situation, problems and Countermeasures of Commodity Housing Market in Wanzhou District, Chongqing. Infrastructure Management Optimization, 29(04), 27-37. Retrieved from http://www.cqvip.com/QK/98574X/201704/673783077.html

Yun, C. (2008). The influential factors and empirical research on urban housing prices from our country. Xiamen $\quad$ University, $2008 . \quad$ Retrieved from http://www.wanfangdata.com.cn/details/detail.do?_type=degree\&id=Y1443559 
Zainora, A. M., Norzailawati, M. N., \& Tuminah, P. (2016). A Spatial Analysis on Gis-Hedonic Pricing Model on the Influence of Public Open Space and House Price in Klang Valley, Malaysia. ISPRS - International Archives of the Photogrammetry, Remote Sensing and Spatial Information Sciences, XLI-B8, 829-836. https://doi.org/10.5194/isprs-archives-XLI-B8-829-2016

Zhi-Yi, H. (2009). The Pricing of Commercial Residence's Analysis and Countermeasures Research in Guangzhou. South China University of Technology, 2009.

\section{Copyrights}

Copyright for this article is retained by the author(s), with first publication rights granted to the journal.

This is an open-access article distributed under the terms and conditions of the Creative Commons Attribution license (http://creativecommons.org/licenses/by/4.0/). 